\title{
A MODEL LINKING CORPORATE BRAND, INDUSTRY IMAGE AND COUNTRY OF ORIGIN IMAGE
}

Carmen Lopez, Plymouth Business School, Plymouth University, UK George Balabanis, Cass Business School, City University, UK

\begin{abstract}
The image of the country is an important asset that directly influences the welfare and development of a nation. However, despite the efforts of many boards and industry associations in their communications to promote a country's image very little is known about the cumulative process and sources that shape a country's image. Most of the current research treats a county's image as an exogenous variable and is concentrated on its consequences and the possible ways for it to be exploited. The proposed research seeks to address this gap in the literature by analysing the impact of a country's corporations and industry image on their county's image.

This study focuses on the case of Spain and is based on empirical evidence provided by collecting qualitative and quantitative data from a face-to-face survey. For the purpose of this study three industries were considered, namely the automobile industry, the fashion industry and the tourism industry. Findings reveal that (1) the breadth of a country's corporations in consumers' memory affects the industry image of a country and (2) the specific industry images of a country at varying degrees affect the image of the country. This study extends previous research by analysing corporate brand, industry image and country of origin image simultaneously in an integrative model. The methodological approach and the findings from the empirical analysis complement extant research on the country branding literature.
\end{abstract}

